\title{
MicroRNA-663 suppresses the proliferation and invasion of colorectal cancer cells by directly targeting FSCN1
}

\author{
SHAOJUN YU, HAITING XIE, JINGJING ZHANG, DA WANG, YONGMAO SONG, \\ SUZHAN ZHANG, SHU ZHENG and JIAN WANG \\ Department of Surgical Oncology, The Second Affiliated Hospital, Zhejiang University \\ School of Medicine, Hangzhou, Zhejiang 310009, P.R. China
}

Received September 30, 2016; Accepted August 2, 2017

DOI: $10.3892 / \mathrm{mmr} .2017 .7794$

\begin{abstract}
Colorectal cancer (CRC) is the most frequently diagnosed malignancy of the gastrointestinal tract. The dysregulation of microRNAs (miRNAs/miRs) has been reported in the majority of types of human cancer, and is correlated with tumorigenesis and tumor development. Abnormal expression of miR-663 has been observed in various types of human cancer. However, little is known about its role in CRC. Therefore, the aim of the present study was to clarify the expression and potential role of miR-663, and its underlying molecular mechanism in CRC. It was observed that miR-663 was markedly downregulated in CRC tissues and cell lines. Decreased miR-663 expression levels in CRC tissues were correlated with tumor, node, metastasis stage and lymph node metastasis. Functional assays revealed that upregulation of miR-663 inhibited cell proliferation and invasion in CRC. Further molecular mechanism assays demonstrated the fascin (FSCN1) was a target gene of miR-663. In addition, FSCN1 was increased and negatively correlated with miR-663 expression in CRC tissues. FSCN1 underexpression mimicked the tumor suppressive functions induced by miR-663 overexpression on CRC cell proliferation and invasion. Collectively, the present study presented evidence that miR-663 may act as a tumor suppressor in CRC by directly targeting FSCN1, which may lead to a potential therapeutic strategy focusing on miR-663 and FSCN1 for patients with this disease.
\end{abstract}

\section{Introduction}

Colorectal cancer (CRC) originates from the epithelial cells of the colon or rectum, and is the most frequently diagnosed malignancy of the gastrointestinal tract $(1,2)$. Numerous risk

Correspondence to: Professor Jian Wang, Department of Surgical Oncology, The Second Affiliated Hospital, Zhejiang University School of Medicine, 88 Jiefang Road, Hangzhou, Zhejiang 310009, P.R. China

E-mail: wangjian519@zju.edu.cn

Key words: colorectal cancer, fascin, microRNA-663 factors involved in $\mathrm{CRC}$ initiation and progression have been identified, including older age, hereditary components, obesity, excess alcohol and red meat consumption, smoking and a lack of physical exercise (3-6). Despite rapid development in the variety of treatment methods and approaches that have been used for patients with CRC, including surgical resection, radiotherapy and chemotherapy, the overall survival of patients with CRC has not notably changed (7). A total of $~ 30-50 \%$ of patients with CRC develop local tumor recurrence or distant metastasis following surgical resection $(8,9)$. Therefore, it is important to elucidate the mechanisms underlying the initiation and progression of $\mathrm{CRC}$, and to investigate novel therapeutic strategies for patients with CRC.

MicroRNAs (miRNAs/miRs) are an abundant group of endogenous, non-coding and evolutionarily-conserved RNAs consisting of 17 to 23 nucleotides in length (10). miRNAs posttranscriptionally regulate gene expression by directly binding to the complementary sequences in the 3'untranslated regions (3'UTRs) of their target genes and inducing gene degradation and/or mRNA translation inhibition $(11,12)$. Previous studies have demonstrated that miRNAs are involved in a number of cancer-associated biological processes, including cell proliferation, apoptosis, the cell cycle, invasion, migration and metastasis (13-15). Notably, miRNA dysregulation has been reported in the majority of types of human cancer, including bladder cancer (16), prostate cancer (17), glioma (18), gastric cancer (19) and osteosarcoma (20). Previous studies have revealed that abnormally expressed miRNAs may be correlated with tumorigenesis and tumor development $(21,22)$. Therefore, miRNAs may be developed as therapeutic targets for novel treatment strategies against CRC.

In the present study, the miR-663 expression level and its association with clinicopathological factors in CRC was investigated. In addition, the biological roles and underlying mechanisms of miR-663 in the carcinogenesis and progression of CRC were evaluated.

\section{Materials and methods}

Tissue specimens and cell lines. CRC tissues $(\mathrm{n}=48)$ and corresponding adjacent normal tissues were collected from the Department of Surgical Oncology, The Second Affiliated Hospital, Zhejiang University School of Medicine (Hangzhou, 
China) between August 2012 and May 2014. No patients were treated with systemic or local treatments prior to surgical resection. All tissue samples were frozen in liquid nitrogen immediately and stored at $-80^{\circ} \mathrm{C}$. The present study was approved by the Ethical Committee of The Second Affiliated Hospital, Zhejiang University School of Medicine. Informed consent was obtained from all patients.

The 293T cell line, a human normal colon epithelial cell line (FHC), and human CRC cell lines (SW620, SW480, LoVo, HCT116, HT29) were purchased from the American Type Culture Collection (Manassas, VA, USA). Cells were cultured in Dulbecco's modified Eagle's medium (Gibco; Thermo Fisher Scientific, Inc., Waltham, MA, USA) with $10 \%$ fetal bovine serum (FBS; Gibco; Thermo Fisher Scientific, Inc.). All cells were maintained at $37^{\circ} \mathrm{C}$ in a humidified environment with $5 \% \mathrm{CO}_{2}$.

Reverse transcription-quantitative polymerase chain reaction (RT-qPCR) analysis. Total RNA from tissues and cells was extracted using TRIzol reagent (Invitrogen; Thermo Fisher Scientific, Inc.). The concentration of total RNA was determined using a NanoDrop ND-1000 Spectrophotometer (Thermo Fisher Scientific, Inc., Wilmington, DE, USA). Total RNA was used to synthesize cDNA using a PrimeScript RT kit (Takara Bio, Inc., Otsu, Japan). A SYBR PrimeScript miRNA RT-qPCR kit (Takara Bio, Inc.) was used to analyze miR-663 expression, with U6 as an internal control. The thermocycling conditions were as follows: $42^{\circ} \mathrm{C}$ for $5 \mathrm{~min} ; 95^{\circ} \mathrm{C}$ for $10 \mathrm{sec}$, followed by 40 cycles of $95^{\circ} \mathrm{C}$ for $5 \mathrm{sec}, 55^{\circ} \mathrm{C}$ for $30 \mathrm{sec}$ and $72^{\circ} \mathrm{C}$ for $30 \mathrm{sec}$. Relative levels of fascin (FSCN1) mRNA were examined using SYBR Green PCR Master Mix (Applied Biosystems; Thermo Fisher Scientific, Inc.), with GADPH as an internal control. The thermocycling conditions were as follows: $95^{\circ} \mathrm{C}$ for $10 \mathrm{~min}$; followed by 40 cycles of $95^{\circ} \mathrm{C}$ for $15 \mathrm{sec}$ and $60^{\circ} \mathrm{C}$ for $1 \mathrm{~min}$. The primers were designed as follows: miR-663 forward, 5'-TGCGGAGGCGGGGCG CCGCGGG-3' and reverse, 5'-CCAGTGCAGGGTCCGAGG T-3'; U6 forward, 5'-GCTTCGGCAGCACATATACTAAAA T-3' and reverse, 5'-CGCTTCACGAATTTGCGTGTCAT-3'; FSCN1 forward, 5'-CTGGCTACACGCTGGAGTTC-3' and reverse 5'-CTGAGTCCCCTGCTGTCTCCT-3'; and GAPDH forward, 5'-CGGAGTCAACGGATTTGGTCGTAT-3' and reverse 5'-AGCCTTCTCCATGGTGGTGAAGAC-3'. The relative expression was analyzed using the $2^{-\Delta \Delta \mathrm{Ca}}$ method (23).

miRNA mimics and small interfering (si)RNA transfection. Oligonucleotides of human miR-663 mimics and miRNA negative control (miR-NC) were synthesized by Shanghai GenePharma Co., Ltd. (Shanghai, China). The miR-663 mimics sequence was 5'-AGGCGGGGCGCCGCGGGACCG C-3' and the miR-NC sequence was 5'-UUCUCCGAACGU GUCACGUTT-3'. FSCN1 siRNA and negative control siRNA (NC siRNA) were obtained from Guangzhou RiboBio Co., Ltd. (Guangzhou, China). The FSCN1 siRNA sequence was 5'-AGCCCTGGGCGTGTAGTGTAA-3' and the NC siRNA sequence was 5'-UUCUCCGAACGUGUCACGUTT-3'. Cells were transfected with miRNA mimics (100 pmol) or siRNA (100 pmol) using Lipofectamine 2000 (Thermo Fisher Scientific, Inc.), according to the manufacturer's protocol. Following transfection for $48 \mathrm{~h}$, RT-qPCR was used to examine the transfection efficiency, according to the same protocol described above.

Cell Counting Kit-8 (CCK8) assay. Cell proliferation was assessed using a CCK8 assay (Dojindo Molecular Technologies, Inc., Kumamoto, Japan). The transfected cells were collected and seeded in 96-well plates in triplicate, at a density of 3,000 cells/well. Cells were incubated at $37^{\circ} \mathrm{C}$ in a humidified environment with $5 \% \mathrm{CO}_{2}$. The CCK8 assay was performed at 24, 48, 72 and $96 \mathrm{~h}$. A total of $10 \mu \mathrm{l} \mathrm{CCK} 8$ solution was added to each well and, following $4 \mathrm{~h}$ of incubation at $37^{\circ} \mathrm{C}$, the absorbance at $450 \mathrm{~nm}$ was determined using a microplate reader (Bio-Rad 550; Bio-Rad Laboratories, Inc., Hercules, CA, USA).

Transwell invasion assay. Cell invasion was assessed using 24-well, 8-mm pore size BD Matrigel invasion chambers (BD Biosciences, Franklin Lakes, NJ, USA), according to the manufacturer's protocol. Transfected cells were collected and re-suspended in FBS-free culture medium. Subsequently, $1 \times 10^{5}$ cells were plated in the upper chamber and the lower chamber was filled with culture medium containing $20 \%$ FBS. Following incubation for $48 \mathrm{~h}$, non-invaded cells were removed using cotton swabs. Invaded cells were fixed with 95\% methanol at room temperature for $10 \mathrm{~min}$ and stained with $0.5 \%$ crystal violet at room temperature for $10 \mathrm{~min}$. Cells in five random fields were photographed and counted under an inverted microscope (magnification, x200; X71; Olympus Corporation, Tokyo, Japan), and data are expressed as the average number of invaded cells/field of view.

Target gene prediction. TargetScan (www.targetscan. org/vert_60) and PicTar (pictar.mdc-berlin.de) were used to predict potential target genes of miR-663.

Luciferase reporter assay. The wild-type (Wt) and mutant (Mut) 3'UTR of FSCN1 was synthesized and subcloned into the pMIR-reporter (GenePharma, Shanghai, China). 293T cells were seeded in 24-well plates in triplicate at a density of $1.5 \times 10^{5}$ cells/well. Following incubation overnight, cells were co-transfected with pMIR-FSCN1-3'UTR Wt or pMIR-FSCN1-3'UTR Mut with miR-663 mimics or miR-NC, using Lipofectamine 2000, according to the manufacturer's protocol. Cells were harvested at $48 \mathrm{~h}$ post-transfection and subjected to a Dual-Luciferase Reporter Assay System (Promega Corporation, Madison, WI, USA). The results were normalized by comparing with Renilla luciferase activity.

Western blot analysis. Total protein was extracted from cells using radioimmunoprecipitation assay buffer (Thermo Fisher Scientific, Inc.) supplemented with phenylmethanesulfonyl fluoride and a cocktail of protease inhibitors (Beyotime Institute of Biotechnology, Haimen, China). The total protein concentration was detected using the bicinchoninic acid method (Beyotime Institute of Biotechnology). Equal quantities of protein $(30 \mu \mathrm{g})$ were separated using SDS-PAGE on a $10 \%$ gel, transferred to a polyvinylidene fluoride membrane (EMD Millipore, Billerica, MA, USA) and blocked with TBS containing $0.1 \%$ Tween-20 (TBST) and 5\% non-fat dried milk at room temperature for $2 \mathrm{~h}$. Subsequently, the membranes were incubated with mouse 
Table I. Correlation between miR-663 expression and clinicopathological features in colorectal cancer.

\begin{tabular}{|c|c|c|c|c|}
\hline \multirow[b]{2}{*}{ Clinicopathological features } & \multirow[b]{2}{*}{ No. cases } & \multicolumn{2}{|c|}{ miR-663 expression } & \multirow[b]{2}{*}{ P-value } \\
\hline & & Low & High & \\
\hline Sex & & & & 0.074 \\
\hline Male & 31 & 21 & 10 & \\
\hline Female & 17 & 7 & 10 & \\
\hline Age, years & & & & 0.836 \\
\hline$<60$ & 16 & 9 & 7 & \\
\hline$\geq 60$ & 32 & 19 & 13 & \\
\hline TNM stage & & & & 0.005 \\
\hline I-II & 27 & 11 & 16 & \\
\hline III-IV & 21 & 17 & 4 & \\
\hline Tumor size, $\mathrm{cm}$ & & & & 0.762 \\
\hline$<5$ & 18 & 10 & 8 & \\
\hline$\geq 5$ & 30 & 18 & 12 & \\
\hline Lymph node metastasis & & & & 0.027 \\
\hline No & 27 & 12 & 15 & \\
\hline Yes & 21 & 16 & 5 & \\
\hline
\end{tabular}

miR, microRNA; TNM, tumor, node, metastasis.
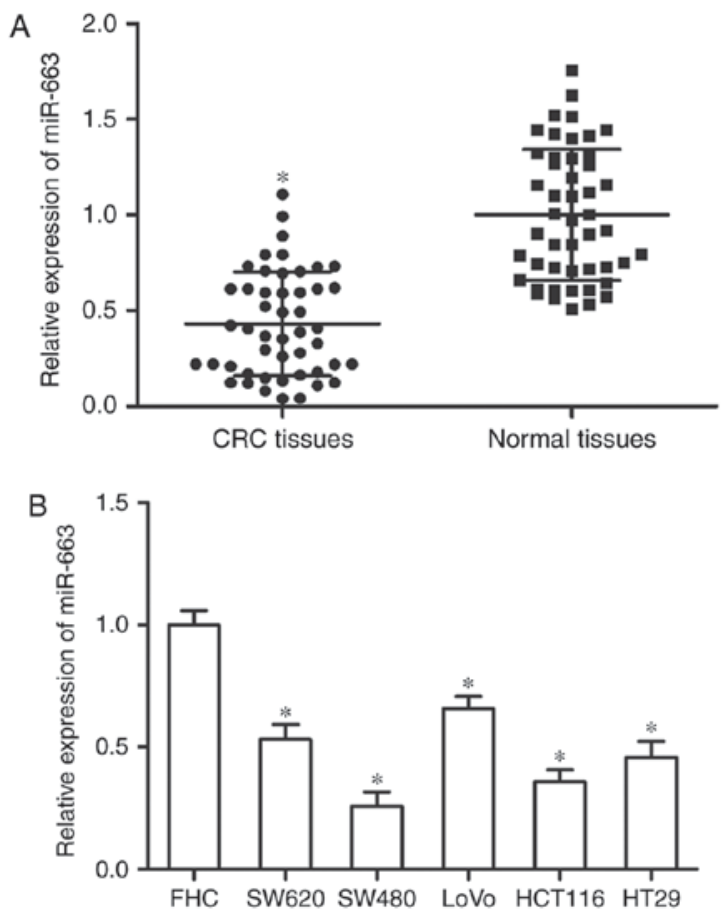

Figure 1. miR-663 is downregulated in CRC tissues and cell lines. (A) The expression of miR-663 in CRC tissues and adjacent normal tissues was detected using RT-qPCR analysis. "P $<0.05$ vs. normal tissues. (B) RT-qPCR analysis of miR-663 expression in CRC cell lines and human normal colon epithelium cell line (FHC). ${ }^{\prime} \mathrm{P}<0.05$ vs. FHC. miR, microRNA; CRC, colorectal cancer; RT-qPCR, reverse transcription-quantitative polymerase chain reaction.

anti-human monoclonal FSCN1 antibody (1:1,000 dilution; cat. no. sc-21743; Santa Cruz Biotechnology, Inc., Dallas, TX, USA) and mouse anti-human monoclonal GADPH antibody (1:1,000 dilution; cat. no. sc-137179; Santa Cruz Biotechnology, Inc.), at $4^{\circ} \mathrm{C}$ overnight.

Following washing three times with TBST every $10 \mathrm{~min}$, membranes were further probed with goat anti-mouse horseradish peroxidase-conjugated secondary antibody $(1: 2,000$ dilution; cat. no. sc-2005; Santa Cruz Biotechnology, Inc.) at room temperature for $1 \mathrm{~h}$ and washed with TBST three times for $10 \mathrm{~min}$. The protein expression level was measured using Enhanced Chemiluminescence Prime Western Blotting Detection Reagent (GE Healthcare Life Sciences, Little Chalfont, UK). GAPDH was used as a reference.

Statistical analysis. All the data are expressed as mean \pm standard deviation. Data were analyzed using Student's t-tests or one-way analysis of variance (ANOVA) using SPSS 17 software (SPSS Inc., Chicago, IL, USA). A Student-Newman-Keuls test was used as a post hoc test following the ANOVA. $\mathrm{P}<0.05$ was considered to indicate a statistically significant difference.

\section{Results}

Down-regulation of miR-663 correlates with clinicopathological features of human CRC. In order to elucidate miR-663 expression in CRC, its expression was measured in CRC tissues and corresponding adjacent normal tissues using RT-qPCR analysis. As presented in Fig. 1A, miR-663 expression levels were decreased in CRC tissues compared with adjacent normal tissues $(\mathrm{P}<0.05)$. miR-663 expression was additionally determined in CRC cell lines and a human normal colon epithelium cell line (FHC). As presented in Fig. 1B, miR-663 expression in $\mathrm{CRC}$ cell lines was decreased compared with that in the FHC cell line $(\mathrm{P}<0.05)$. 

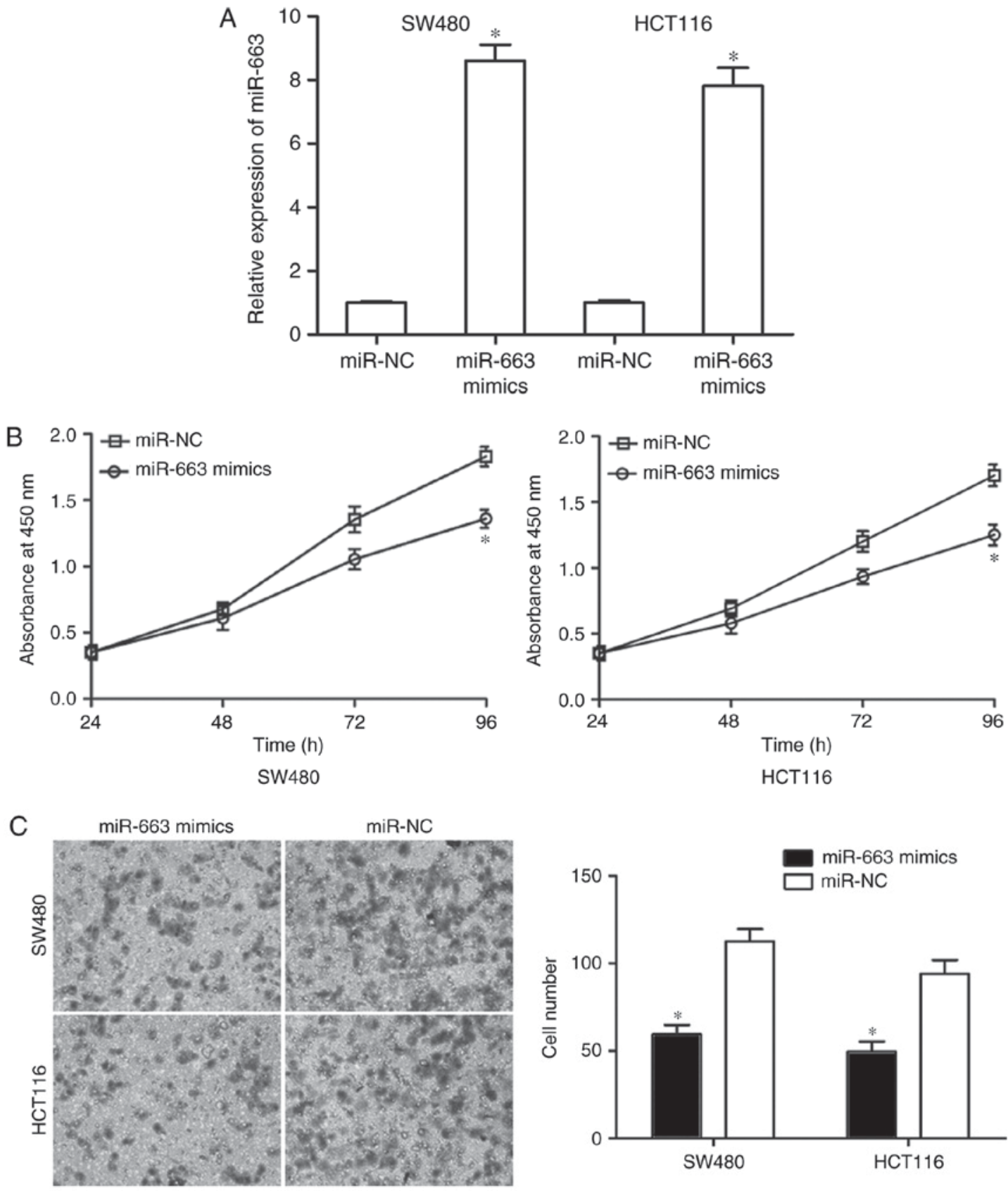

Figure 2. miR-663 suppresses the proliferation and invasion of SW480 and HCT116 cells. (A) The expression of miR-663 in SW480 and HCT116 cells transfected with miR-663 mimics or miR-NC was measured using the reverse transcription-quantitative polymerase chain reaction. (B) The proliferation of SW480 and HCT116 cells following transfection with miR-663 mimics or miR-NC was detected by using a Cell Counting Kit-8 assay. (C) The invasive capacity of SW480 and HCT116 cells following transfection with miR-663 mimics or miR-NC was determined using a Transwell invasion assay. "P<0.05 vs. miR-NC. miR, microRNA; NC, negative control.

Subsequently, the association between miR-663 expression and clinicopathological features in patients with CRC was analyzed. As presented in Table I, decreased miR-663 expression in CRC tissues was significantly correlated with tumor, node, metastasis (TNM) stage $(\mathrm{P}=0.005)$ and lymph node metastasis $(\mathrm{P}=0.027)$, while there was no correlation with gender, age and tumor size. The results of the present study suggested that miR-663 may serve important roles in CRC.

miR-663 suppresses cell proliferation and invasion in CRC. In order to evaluate the functions of miR-663 in CRC, SW480 and HCT116 cells were transfected with miR-663 mimics or miR-NC. Following transfection for $48 \mathrm{~h}, \mathrm{RT}-\mathrm{qPCR}$ analysis confirmed that miR-663 expression was significantly increased in SW480 and HCT116 cells transfected with miR-663 mimics (Fig. 2A; $\mathrm{P}<0.05$ ).

CCK8 and Transwell invasion assay were used to assess the effects of miR-663 overexpression on the cell proliferation and invasiveness of CRC, respectively. As presented in Fig. 2B, the proliferation of SW480 and HCT116 cells was significantly decreased by miR-663 overexpression $(\mathrm{P}<0.05)$. The results of the Transwell invasion assay demonstrated that invasive capacity was significantly limited in SW480 and HCT116 


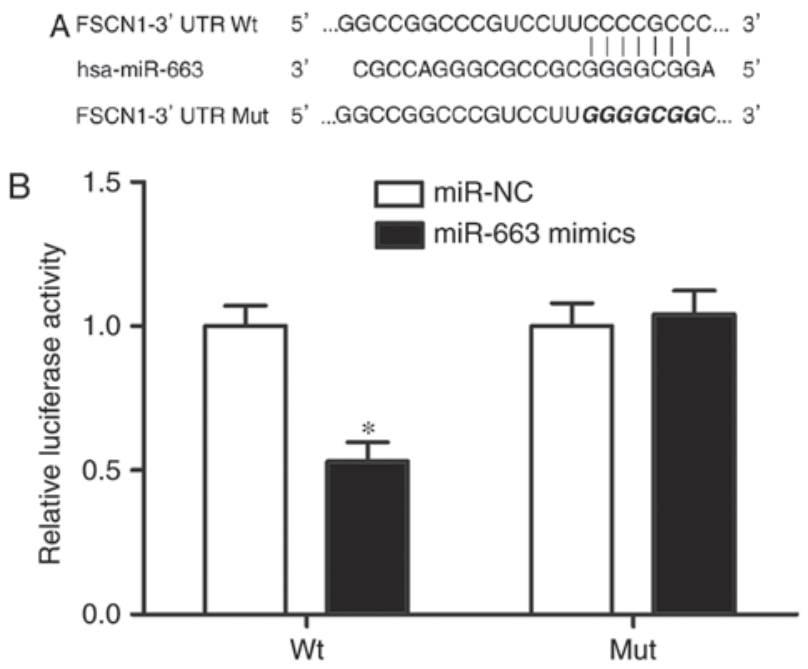

Figure 3. Identification of FSCN1 as a miR-663 target gene. (A) Schematic representation of the human FSCN1 3'UTR illustrating the highly-conserved miR-663 binding site. (B) 293T cells were transfected with pMIR-FSCN1-3'UTR Wt or pMIR-FSCN1-3'UTR Mut, with miR-663 mimics or miR-NC. Luciferase and Renilla luciferase activity was determined at $48 \mathrm{~h}$ post-transfection. ${ }^{*} \mathrm{P}<0.05$ vs. miR-NC. FSCN1, fascin; miR, microRNA; UTR, untranslated region; Wt, wild-type; Mut, mutant; NC, negative control.
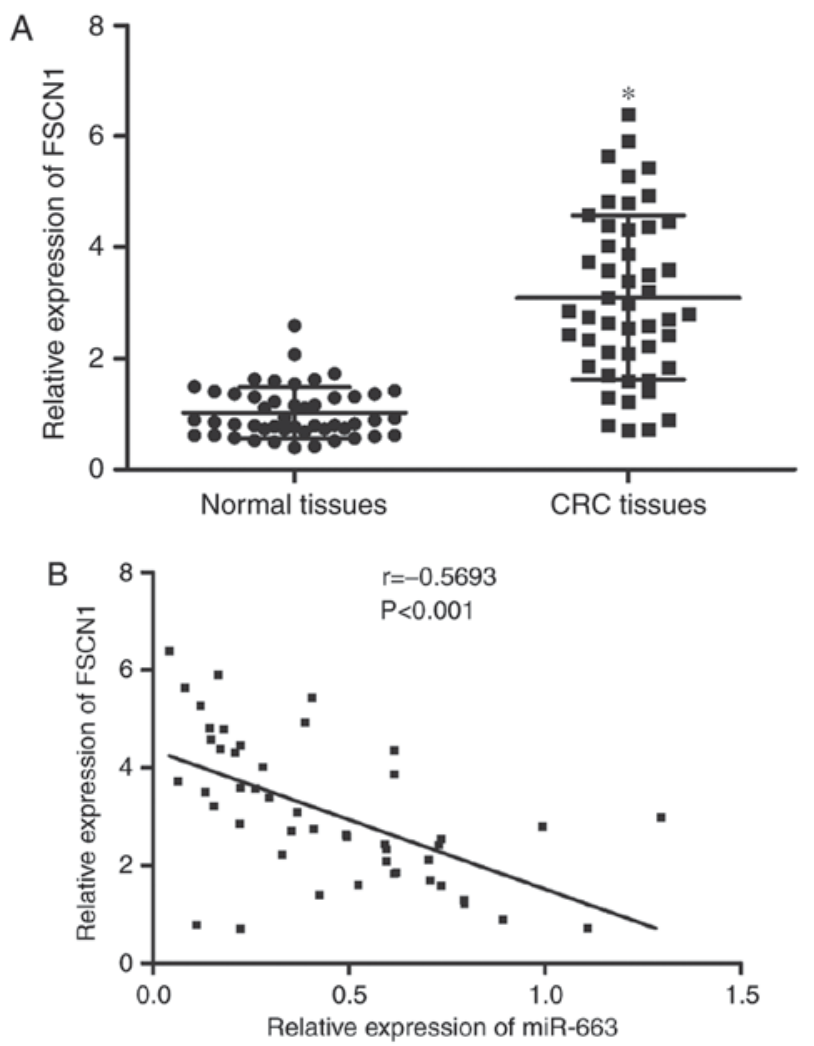

Figure 4. FSCN1 expression is inversely correlated with miR-663 expression in CRC tissues. (A) The expression of FSCN1 mRNA in CRC tissues and adjacent normal tissues was examined by reverse transcription-quantitative polymerase chain reaction analysis. ${ }^{\mathrm{P}}<0.05$ vs. normal tissues. (B) FSCN1 and miR-663 expression levels were demonstrated to be negatively correlated in CRC tissues. FSCN1, fascin; miR, microRNA; CRC, colorectal cancer.

cells transfected with miR-663 mimics compared with cells transfected with miR-NC (Fig. 2C; $\mathrm{P}<0.05$ ).

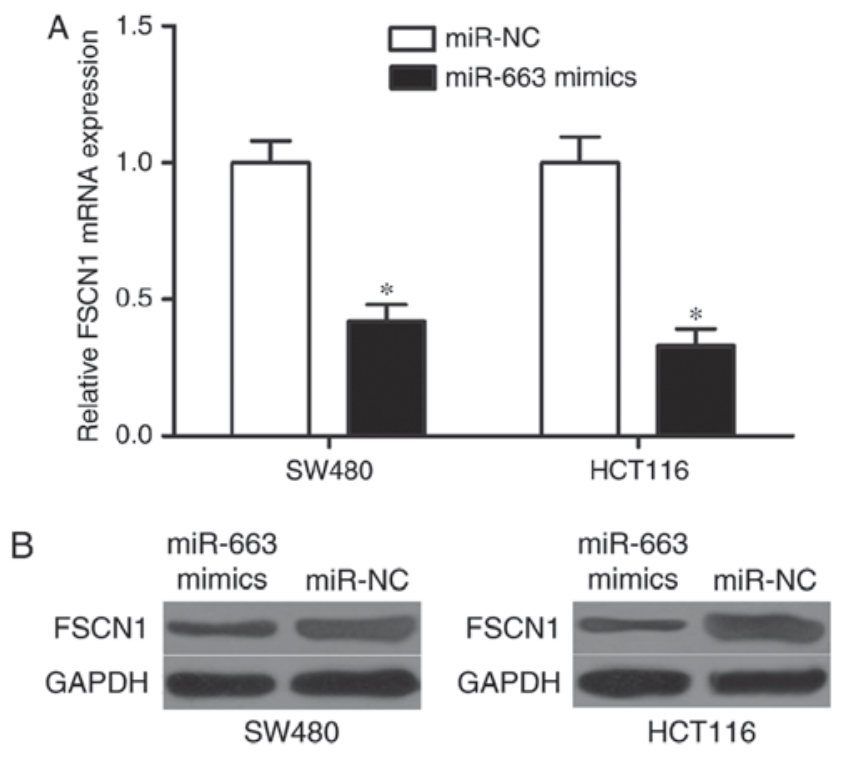

Figure 5. miR-663 overexpression reduces FSCN1 expression in SW480 and HCT116 cells. (A) The expression of FSCN1 mRNA in SW480 and HCT116 cells transfected with miR-663 mimics or miR-NC was measured using reverse transcription-quantitative polymerase chain reaction analysis. ${ }^{*} \mathrm{P}<0.05$ vs. miR-NC. (B) Western blot analysis of FSCN1 protein expression in SW480 and HCT116 cells transfected with miR-663 mimics or miR-NC. miR, microRNA; FSCN1, fascin; NC, negative control.

FSCN1 is a direct target of miR-663. In order to examine the potential molecular mechanisms underlying the role of miR-663 in the regulation of cell proliferation and invasion in CRC, TargetScan and PicTar were used to predicate its potential target genes. As presented in Fig. 3A, there are seven conserved binding sites for miR-663 in the 3'UTR region of FSCN1.

A luciferase reporter assay was subsequently performed in 293T cells co-transfected with miR-663 mimics or miR-NC, and pMIR-FSCN1-3'UTR Wt or pMIR-FSCN1-3'UTR Mut. As presented in Fig. 3B, upregulation of miR-663 decreased the luciferase activity of pMIR-FSCN1-3'UTR Wt $(\mathrm{P}<0.05)$, although not pMIR-FSCN1-3'UTR Mut, indicating that miR-663 specifically targeted the 3'UTR of FSCN1.

FSCN1 is upregulated in CRC tissues and inversely correlates with miR-663 levels in CRC tissues. In order to further confirm that FSCN1 is a direct target of miR-663, the FSCN1 expression levels were detected in CRC tissues and corresponding adjacent normal tissues. The results demonstrated that FSCN1 was expressed at high levels in CRC tissues compared with adjacent normal tissues (Fig. 4A; $\mathrm{P}<0.05$ ) and was negatively correlated with miR-663 expression levels in CRC tissues (Fig. 4B; r=-0.5693; $\mathrm{P}<0.001$ ).

miR-663 negatively regulates FSCN1 expression in CRC cells. RT-qPCR and western blot analyses were used to examine the alterations in endogenous FSCN1 mRNA and protein expression in SW480 and HCT116 cells, following transfection with miR-663 mimics or miR-NC. As presented in Fig. 5A and $\mathrm{B}$, compared with miR-NC, restoration of the expression of miR-663 reduced FSCN1 expression in SW480 and HCT116 
A

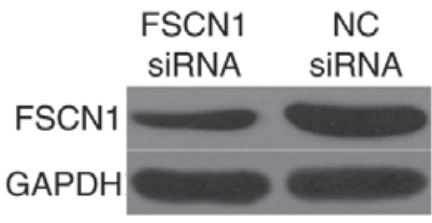

SW480

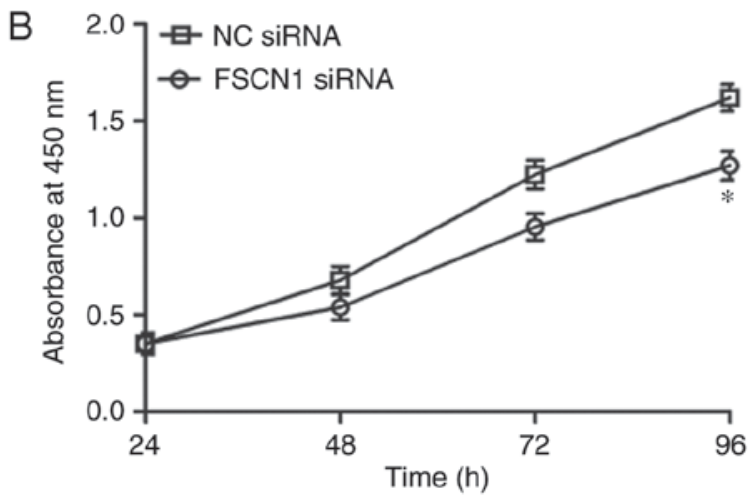

SW480

C

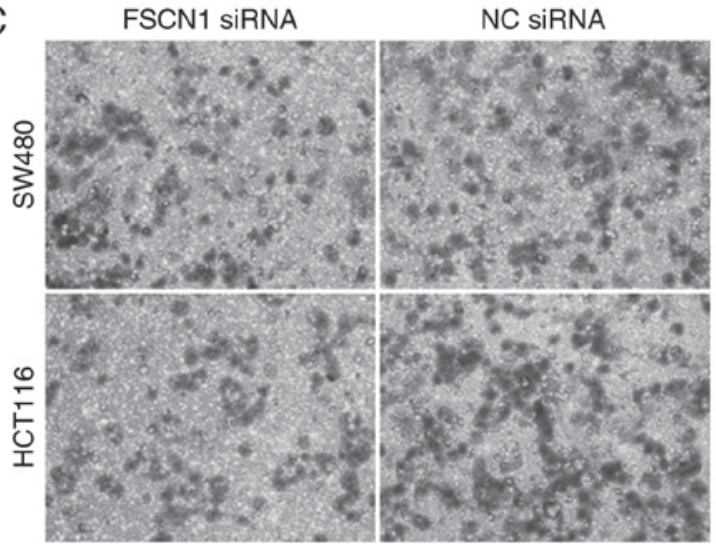

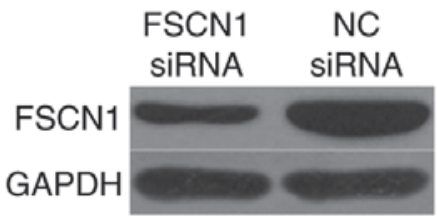

HCT116
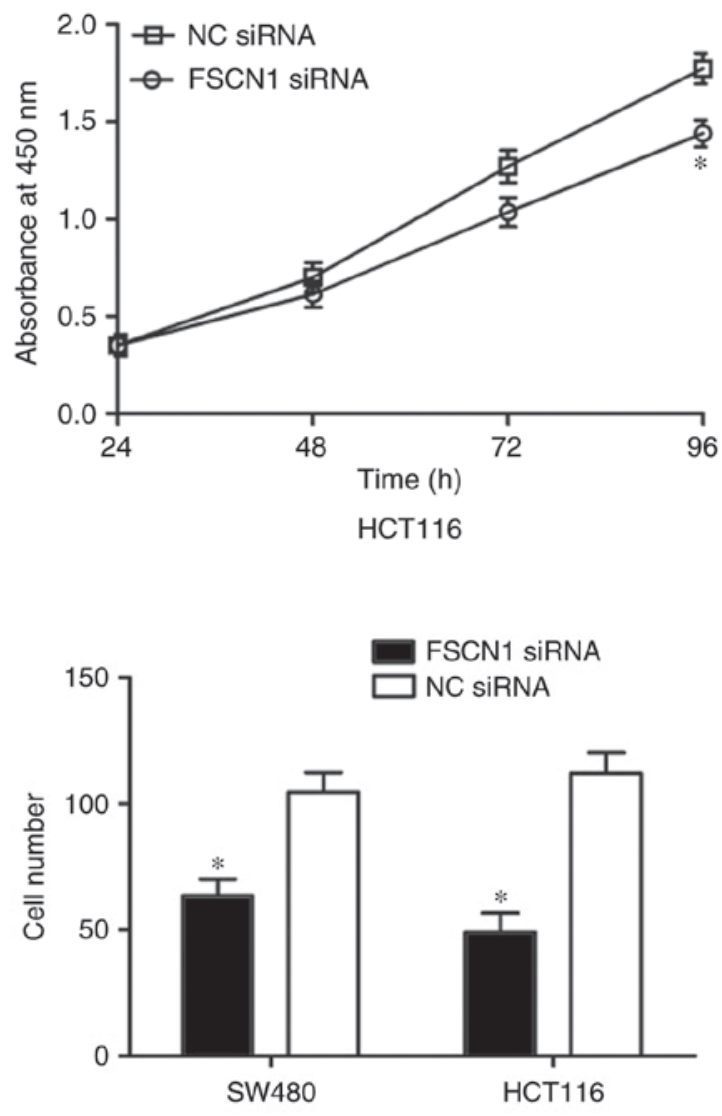

Figure 6. Downregulation of FSCN1 suppresses the proliferation and invasion of SW480 and HCT116 cells. (A) The expression of FSCN1 protein in SW480 and HCT116 cells transfected with FSCN1 siRNA or NC siRNA was detected using western blot analysis. (B) The proliferation of SW480 and HCT116 cells following transfection with FSCN1 siRNA or NC siRNA was detected using a Cell Counting Kit-8 assay. (C) The invasive ability of SW480 and HCT116 cells following transfection with FSCN1 siRNA or NC siRNA was determined by a Transwell invasion assay. ${ }^{*} \mathrm{P}<0.05$ vs. NC siRNA. FSCN1, fascin; siRNA, small interfering RNA; NC, negative control.

cells at the mRNA and protein levels $(\mathrm{P}<0.05)$. The results of the present study suggested that miR-663 negatively regulated FSCN1 expression in CRC cells by directly targeting the 3'UTR of FSCN1.

FSCN1 underexpression simulates the tumor suppressor function of miR-663 mimics in CRC cells. As FSCN1 is a direct target of miR-663 in CRC, the biological role of FSCN1 in the cell proliferation and invasiveness of $\mathrm{CRC}$ was investigated. FSCN1 siRNA was transfected into SW480 and HCT116 cells to decrease its expression (Fig. 6A). Subsequently, CCK8 and Transwell invasion assays were performed. As presented in Fig. 6B and C, FSCN1 underexpression suppressed the proliferation $(\mathrm{P}<0.05)$ and invasion $(\mathrm{P}<0.05)$ of $\mathrm{SW} 480$ and HCT116 cells, which was consistent with the effects of miR-663 mimics. The results of the present study suggested that the tumor-suppressive role of miR-663 is mediated via downregulation of FSCN1 in CRC.

\section{Discussion}

miR-663 has been observed to be aberrantly expressed in numerous types of human cancer. For example, in glioblastoma, miR-663 expression was inhibited in tumor tissues and cell lines (24) and it was demonstrated to be a poor prognostic marker in patients with glioblastoma (25). In pancreatic cancer, the expression level of miR-663 was decreased and was significantly correlated with TNM stage and the lymph node metastasis status of patients (26). Pan et al (27) demonstrated that miR-663 expression was decreased in gastric cancer cell lines compared with normal cells. In papillary thyroid carcinoma, miR-663 was downregulated in tumor tissues and cell lines; in addition, there was statistically significant differences in the expression level of miR-663 with regard to age and tumor size (28). However, in castration-resistant prostate cancer, miR-663 was demonstrated to be overexpressed; increased miR-663 expression was associated with Gleason score and 
TNM stage, and was an independent prognostic predictor of clinical recurrence (29). Previous studies additionally demonstrated that miR-663 was increased in nasopharyngeal carcinoma tissues (30), lung cancer (31), breast cancer (32) and hepatocellular carcinoma (33).

miR-663 may act as either a tumor suppressor or promoter in human malignancies. Li et al (24) reported that enforced miR-663 expression attenuated cell proliferation, migration and invasion of glioblastoma through downregulation of transforming growth factor (TGF)- $\beta 1$. Shi et al $(25,34)$ demonstrated that ectopic miR-663 expression decreased the proliferative and invasive capacities of glioblastoma cells by targeting C-X-C chemokine receptor type 4 and phosphatidylinositol 4,5-bisphosphate 3-kinase catalytic subunit delta isoform. In vitro and in vivo experiments demonstrated that restoration of the expression of miR-663 inhibited cell proliferation and invasion in pancreatic cancer via inhibition of elongation factor 1- $\alpha 2$ (26). A study by Wang et al (28) demonstrated that miR-663 overexpression decreased papillary thyroid carcinoma cell migration and invasion by directly targeting TGF- $\beta 1$. miR-663 was additionally identified to be an oncogene in a number of types of human cancer. For example, in nasopharyngeal carcinoma, downregulation of miR-663 suppressed cell proliferation in vitro and tumor growth in vivo through negative regulation of cyclin-dependent kinase inhibitor 1 (30). In hepatocellular carcinoma, miR-663 underexpression impaired cell proliferation and promoted apoptosis under endoplasmic reticulum stress by targeting TGF- $\beta 1$ (33). These conflicting findings indicated that the expression and functions of miR-663 in tumors are diverse and tissue-specific.

The present study used multi-dimensional approaches to demonstrate that FSCN1 is a direct downstream target of miR-663. Bioinformatics analysis indicated that FSCN1 was a potential target gene of miR-663. Through the luciferase reporter assay, it was observed that the 3'UTR of FSCN1 was directly targeted by miR-663. It was additionally demonstrated that FSCN1 was significantly upregulated in clinical CRC tissues and was inversely correlated with the miR-663 expression level. Ectopic miR-663 expression decreased endogenous FSCN1 expression at the mRNA and protein level in CRC cells. Additionally, siRNA was used to specifically knock down FSCN1 in CRC cells, demonstrated that it was able to simulate the tumor suppressor functions induced by miR-663 overexpression in the cell proliferation and invasion of CRC. The results of the present study demonstrated that miR-663 may act as a tumor suppressor in CRC by directly targeting FSCN1.

FSCN1, a 55-kDa globular protein, is an actin-bundling protein and is well-established as an integral component of invadopodia, which stabilize actin bundles in invasive foot structures (35). A number of previous studies have reported that FSCN1 is overexpressed in human cancer, including prostate cancer (36), lung cancer (37), breast cancer (38), gastric carcinoma (39), esophageal cancer (40) and pancreatic cancer (41). Increased FSCN1 expression was correlated with aggressive clinical course, poor prognosis and shorter survival for patients with these types of cancer. FSCN1 has been observed to be upregulated in human CRC. An increased expression level of FSCN1 was significantly associated with reduced overall survival and reduced disease-free survival; patients with CRC exhibiting increased FSCN1 levels had worse overall survival and disease-free survival compared with patients with low FSCN1 (42). FSCN1 expression in CRC may be clinically useful for predicting metastasis and poor survival (43). With the emerging correlation of FSCN1 with aggressive CRC progression, FSCN1 may be developed as a therapeutic target for patients with this disease. The results of the present study demonstrated that miR-663/FSCN1 based reagents may be a novel therapeutic approach for CRC patients.

In conclusion, the present study confirmed that miR-663 acted as a tumor suppressor gene by inhibiting CRC cell growth and invasion, via direct targeting of FSCN1. The results of the present study provided novel evidence for the potential utility of a miR-663/FSCN1-based targeted therapy in the treatment of CRC.

\section{References}

1. East JE and Dekker E: Colorectal cancer diagnosis in 2012: A new focus for CRC prevention-more serration, less inflammation. Nat Rev Gastroenterol Hepatol 10: 69-70, 2013.

2. Jemal A, Bray F, Center MM, Ferlay J, Ward E and Forman D: Global cancer statistics. CA Cancer J Clin 61: 69-90, 2011.

3. Andrews L: Dietary flavonoids for the prevention of colorectal cancer. Clin J Oncol Nurs 17: 671-672, 2013.

4. Altobelli E, Lattanzi A, Paduano R, Varassi G and di Orio F: Colorectal cancer prevention in Europe: Burden of disease and status of screening programs. Prev Med 62: 132-141, 2014.

5. Sugarbaker PH: Colorectal cancer: Prevention and management of metastatic disease. Biomed Res Int 2014: 782890, 2014.

6. Chan DS, Lau R, Aune D, Vieira R, Greenwood DC, Kampman E and Norat T: Red and processed meat and colorectal cancer incidence: Meta-analysis of prospective studies. PLoS One 6: e20456, 2011.

7. Wei ZJ, Tao ML, Zhang W, Han GD, Zhu ZC, Miao ZG, Li JY and Qiao ZB: Up-regulation of microRNA-302a inhibited the proliferation and invasion of colorectal cancer cells by regulation of the MAPK and PI3K/Akt signaling pathways. Int J Clin Exp Pathol 8: 4481-4491, 2015.

8. Amano R, Yamada N, Nakata B, Kimura K, Yashiro M, Ohira $M$ and Hirakawa K: Prognostic indicator for the resection of liver metastasis of colorectal cancer. Surg Today 44: 1287-1292, 2014

9. Lieberman DA, Rex DK, Winawer SJ, Giardiello FM Johnson DA and Levin TR: Guidelines for colonoscopy surveillance after screening and polypectomy: A consensus update by the US multi-society task force on colorectal cancer. Gastroenterology 143: 844-857, 2012.

10. Bartel DP: MicroRNAs: Genomics, biogenesis, mechanism, and function. Cell 116: 281-297, 2004.

11. Lewis BP, Burge CB and Bartel DP: Conserved seed pairing, often flanked by adenosines, indicates that thousands of human genes are microRNA targets. Cell 120: 15-20, 2005.

12. Lai EC: Micro RNAs are complementary to 3' UTR sequence motifs that mediate negative post-transcriptional regulation. Nat Genet 30: 363-364, 2002.

13. Ostenfeld MS, Bramsen JB, Lamy P, Villadsen SB, Fristrup N Sørensen KD, Ulhøi B, Borre M, Kjems J, Dyrskjøt L and Orntoft TF: miR-145 induces caspase-dependent and -independent cell death in urothelial cancer cell lines with targeting of an expression signature present in Ta bladder tumors. Oncogene 29: 1073-1084, 2010.

14. Lai VK, Ashraf M, Jiang S and Haider K: MicroRNA-143 is a critical regulator of cell cycle activity in stem cells with co-overexpression of Akt and angiopoietin-1 via transcriptional regulation of Erk5/cyclin D1 signaling. Cell Cycle 11: 767-777, 2012.

15. Wu D, Zhou Y, Pan H, Zhou J, Fan Y and Qu P: microRNA-99a inhibiting cell proliferation, migration and invasion by targeting fibroblast growth factor receptor 3 in bladder cancer. Oncol Lett 7: 1219-1224, 2014.

16. Wu WB, Wang W, Du YH, Li H, Xia SJ and Liu HT: MicroRNA-3713 regulates bladder cell invasion via MMP9. Sci Rep 6: 32374, 2016. 
17. Feng S, Zhu X, Fan B, Xie D, Li T and Zhang X: miR-19a-3p targets PMEPA1 and induces prostate cancer cell proliferation, migration and invasion. Mol Med Rep 13: 4030-4038, 2016.

18. Wu J, Cui H, Zhu Z and Wang L: MicroRNA-200b-3p suppresses epithelial-mesenchymal transition and inhibits tumor growth of glioma through down-regulation of ERK5. Biochem Biophys Res Commun 478: 1158-1164, 2016.

19. Wang H, Xiong M, Hu Y, Sun Y and Ma Q: MicroRNA-19b inhibits proliferation of gastric cancer cells by targeting B-cell CLL/lymphoma 3. Oncol Rep 36: 2079-2086, 2016.

20. Dong J, Liu Y, Liao W, Liu R, Shi P and Wang L: miRNA-223 is a potential diagnostic and prognostic marker for osteosarcoma. J Bone Oncol 5: 74-79, 2016.

21. Lu J, Getz G, Miska EA, Alvarez-Saavedra E, Lamb J, Peck D, Sweet-Cordero A, Ebert BL, Mak RH, Ferrando AA, et al: MicroRNA expression profiles classify human cancers. Nature 435: 834-838, 2005.

22. Volinia S, Calin GA, Liu CG, Ambs S, Cimmino A, Petrocca F, Visone R, Iorio M, Roldo C, Ferracin M, et al: A microRNA expression signature of human solid tumors defines cancer gene targets. Proc Natl Acad Sci USA 103: 2257-2261, 2006.

23. Livak KJ and Schmittgen TD: Analysis of relative gene expression data using real-time quantitative PCR and the 2(-Delta Delta C(T)) method. Methods 25: 402-408, 2001.

24. Li Q, Cheng Q, Chen Z, Peng R, Chen R, Ma Z, Wan X, Liu J, Meng M, Peng $Z$ and Jiang B: MicroRNA-663 inhibits the proliferation, migration and invasion of glioblastoma cells via targeting TGF- $\beta 1$. Oncol Rep 35: 1125-1134, 2016.

25. Shi Y, Chen C, Zhang X, Liu Q, Xu JL, Zhang HR, Yao XH, Jiang T, He ZC, Ren Y, et al: Primate-specific miR-663 functions as a tumor suppressor by targeting PIK3CD and predicts the prognosis of human glioblastoma. Clin Cancer Res 20: 1803-1813, 2014.

26. Zang W, Wang Y, Wang T, Du Y, Chen X, Li M and Zhao G: miR-663 attenuates tumor growth and invasiveness by targeting eEF1A2 in pancreatic cancer. Mol Cancer 14: 37, 2015.

27. Pan J, Hu H, Zhou Z, Sun L, Peng L, Yu L, Sun L, Liu J, Yang Z and Ran Y: Tumor-suppressive mir-663 gene induces mitotic catastrophe growth arrest in human gastric cancer cells. Oncol Rep 24: 105-112, 2010.

28. Wang Z, Zhang H, Zhang P, Dong W and He L: MicroRNA-663 suppresses cell invasion and migration by targeting transforming growth factor beta 1 in papillary thyroid carcinoma. Tumour Biol 37: 7633-7644, 2016.

29. Jiao L, Deng Z, Xu C, Yu Y, Li Y, Yang C, Chen J, Liu Z, Huang G, Li LC and Sun Y: miR-663 induces castration-resistant prostate cancer transformation and predicts clinical recurrence. J Cell Physiol 229: 834-844, 2014.

30. Yi C, Wang Q, Wang L, Huang Y, Li L, Liu L, Zhou X, Xie G, Kang T, Wang H, et al: MiR-663, a microRNA targeting p21(WAF1/CIP1), promotes the proliferation and tumorigenesis of nasopharyngeal carcinoma. Oncogene 31: 4421-4433, 2012.
31. Liu ZY, Zhang GL, Wang MM, Xiong YN and Cui HQ: MicroRNA-663 targets TGFB1 and regulates lung cancer proliferation. Asian Pac J Cancer Prev 12: 2819-2823, 2011.

32. Hu H, Li S, Cui X, Lv X, Jiao Y, Yu F, Yao H, Song E, Chen Y, Wang $M$ and Lin L: The overexpression of hypomethylated miR-663 induces chemotherapy resistance in human breast cancer cells by targeting heparin sulfate proteoglycan 2 (HSPG2). J Biol Chem 288: 10973-10985, 2013.

33. Huang Y, Liu J, Fan L, Wang F, Yu H, Wei W and Sun G: miR-663 overexpression induced by endoplasmic reticulum stress modulates hepatocellular carcinoma cell apoptosis via transforming growth factor beta 1. Onco Targets Ther 9: 1623-1633, 2016.

34. Shi Y, Chen C, Yu SZ, Liu Q, Rao J, Zhang HR, Xiao HL, Fu TW, Long H, He ZC, et al: miR-663 suppresses oncogenic function of CXCR4 in glioblastoma. Clin Cancer Res 21: 4004-4013, 2015.

35. Jayo A and Parsons M: Fascin: A key regulator of cytoskeletal dynamics. Int J Biochem Cell Biol 42: 1614-1617, 2010.

36. Darnel AD, Behmoaram E, Vollmer RT, Corcos J, Bijian K, Sircar K, Su J, Jiao J, Alaoui-Jamali MA and Bismar TA: Fascin regulates prostate cancer cell invasion and is associated with metastasis and biochemical failure in prostate cancer. Clin Cancer Res 15: 1376-1383, 2009.

37. Pelosi G, Pastorino U, Pasini F, Maissoneuve P, Fraggetta F, Iannucci A, Sonzogni A, De Manzoni G, Terzi A, Durante E, et al: Independent prognostic value of fascin immunoreactivity in stage I nonsmall cell lung cancer. Br J Cancer 88: 537-547, 2003.

38. Rodríguez-Pinilla SM, Sarrió D, Honrado E, Hardisson D, Calero F, Benitez J and Palacios J: Prognostic significance of basal-like phenotype and fascin expression in node-negative invasive breast carcinomas. Clin Cancer Res 12: 1533-1539, 2006.

39. Hashimoto Y, Shimada Y, Kawamura J, Yamasaki S and Imamura M: The prognostic relevance of fascin expression in human gastric carcinoma. Oncology 67: 262-270, 2004.

40. Hashimoto Y, Ito T, Inoue H, Okumura T, Tanaka E, Tsunoda S, Higashiyama M, Watanabe G, Imamura M and Shimada Y: Prognostic significance of fascin overexpression in human esophageal squamous cell carcinoma. Clin Cancer Res 11: 2597-2605, 2005.

41. Maitra A, Iacobuzio-Donahue C, Rahman A, Sohn TA, Argani P, Meyer R, Yeo CJ, Cameron JL, Goggins M, Kern SE, et al: Immunohistochemical validation of a novel epithelial and a novel stromal marker of pancreatic ductal adenocarcinoma identified by global expression microarrays: Sea urchin fascin homolog and heat shock protein 47. Am J Clin Pathol 118: 52-59, 2002.

42. Alajez NM: Significance of BMI1 and FSCN1 expression in colorectal cancer. Saudi J Gastroenterol 22: 288-293, 2016.

43. Oh SY, Kim YB, Suh KW, Paek OJ and Moon HY: Prognostic impact of fascin-1 expression is more significant in advanced colorectal cancer. J Surg Res 172: 102-108, 2012. 